\title{
Changes in Glucose Uptake by and Phlorizin Binding to Brush-Border Membrane Vesicles of Small Intestine from Streptozotocin- Induced Diabetic Rats
}

\author{
Yoshimitsu TsuJI, ${ }^{1}$ Kazuhiko YAMAdA, ${ }^{1}$ Norimasa Hosoya,,${ }^{1, *}$ \\ Katsuji TAKAI, ${ }^{1}$ and Sachiko MORIUCHI ${ }^{2}$ (the late) \\ ${ }^{1}$ Department of Nutrition, School of Health Sciences, \\ Faculty of Medicine, University of Tokyo, \\ Bunkyo-ku, Tokyo 113, Japan \\ ${ }^{2}$ Department of Food and Nutrition, School of Home- \\ Economics, Japan Women's University, \\ Bunkyo-ku, Tokyo 112, Japan
}

(Received March 24, 1988)

\begin{abstract}
Summary The changes in the intestinal glucose transport in streptozotocin-induced diabetic rats have been demonstrated with brushborder membrane vesicles. When $\mathrm{Na}^{+}$-dependent D-glucose uptake and phlorizin binding activities were compared, both significantly increased either in the jejunum or ileum of diabetic rats compared with those of control. Kinetic studies showed the increases in the $V_{\max }$ of glucose transport and the maximum binding of phlorizin $\left(B_{\max }\right)$, whereas the $K_{\mathrm{t}}$ and $K_{\mathrm{d}}$ remained unchanged, respectively. These results suggested that the increase in glucose transport in diabetic rat intestine was due to the increase in the number of the intact glucose transporters.
\end{abstract}

Key Words streptozotocin-induced diabetes, brush-border membrane vesicles, glucose uptake, phlorizin binding

D-Glucose is actively cotransported with sodium across the intestinal brushborder membrane via a carrier-mediated process. This carrier cotransports sodium and glucose in a 1:1 tightly coupled manner and is competitively inhibited by phlorizin, a non-transported inhibitor of intestinal monosaccharide transport $(1,2)$. Evidence from many studies indicates that phlorizin specifically binds to the $\mathrm{Na}^{+}$, D-glucose cotransporter of the intestinal brush-border membrane, and competes for the active site on the transporter with glucose.

${ }^{1}$ 辻 義光, 山田和彦, 細谷憲政, 高井克治, ${ }^{2}$ 故森内幸子

* Present address: Research Foundation for Sugar Research, 26-3 Shinbashi 3, Minatoku, Tokyo 105, Japan. 
On the other hand, it has been reported that experimentally induced diabetes causes the increase of $\mathrm{Na}^{+}$-dependent glucose transport (3-5), and also the increase of disaccharidase activities (6-8). In our previous study, we reported that the transmural potential difference ( $\triangle \mathrm{PD})$ on transport of glucose derived from disaccharides was increased in diabetic rats, and this increase was ascribed mainly to the increased activity of glucose transport system, but not the increase of disaccharidase activities (9). However, it is not clear whether the increase of active transport of glucose is due to the increase in the number of glucose transporters or the changes in its properties.

Therefore, we have examined the $\mathrm{Na}^{+}$-dependent glucose uptake by brushborder membrane vesicles from small intestine and high-affinity binding of phlorizin to the transporter in streptozotocin-induced diabetic rats.

\section{MATERIALS AND METHODS}

1. Animals. Male rats of Wistar strain, weighing about $250 \mathrm{~g}$, were injected intraperitoneally with streptozotocin $(70 \mathrm{mg} / \mathrm{kg})$ dissolved in $50 \mathrm{~mm}$ sodium-citrate buffer ( $\mathrm{pH} 4.5$ ). Control rats received the sodium-citrate buffer alone. All rats were housed in individual metabolic cages, and given a standard laboratory chow (Oriental Yeast Co.) and water ad libitum. On day 12 after the injection, the rats were killed by decapitation between 9 to 11 a.m. without fasting. Blood was tested for glucose concentration using the glucose-oxidase method of Dahlqvist (10). The appearance of diabetes was assessed by glucosuria and the blood glucose level higher than $300 \mathrm{mg} / \mathrm{dl}$.

2. Preparation of brush-border membrane vesicles from small intestine. The intestine from the ligament of Treitz to the ileocecal junction was quickly excised, and divided into two segments of equal length: the proximal portion (jejunum), and the distal portion (ileum). Each segment was rinsed with ice-cold saline and then blotted on tissue paper. Mucosa was scraped by a glass slide from each segment. Brush-border membrane vesicles were prepared from mucosa according to the method described previously (1). Mucosa scrapings were suspended in $25 \mathrm{vol}$. of icecold $50 \mathrm{~mm}$ mannitol in $2 \mathrm{~mm}$ Tris- $\mathrm{HCl}$ buffer ( $\mathrm{pH} \mathrm{7.1)}$ and homogenized using a Polytron for $1 \mathrm{~min}$. Calcium chloride was added to the homogenate to give a final concentration of $10 \mathrm{~mm}$. After being kept in the cold for $20 \mathrm{~min}$, the suspension was centrifuged at $3,000 \times g$ for $15 \mathrm{~min}$, and the resulting supernatant was centrifuged at $27,000 \times g$ for $30 \mathrm{~min}$. The pellet was then resuspended in 2 vol. of $100 \mathrm{~mm}$ mannitol in $10 \mathrm{~mm}$ Tris-HEPES ( $N$-2-hydroxyethylpiperazine- $N$ '-2-ethanesulfonic acid) buffer ( $\mathrm{pH} \mathrm{7.5)}$ and centrifuged once more at $27,000 \times g$ for $30 \mathrm{~min}$. The pellet containing almost pure brush-border membrane vesicles was resuspended in $100 \mathrm{~mm}$ mannitol in $10 \mathrm{~mm}$ Tris-HEPES buffer ( $\mathrm{pH} \mathrm{7.5).} \mathrm{The} \mathrm{suspension} \mathrm{contained} \mathrm{about}$ $8-10 \mathrm{mg}$ protein per $\mathrm{ml}$.

3. Measurements of glucose uptake and the phlorizin binding activity of brushborder membrane vesicles. Uptake of glucose by, and phlorizin binding to, brush- 
border membrane vesicles were determined by nitrocellulose-membrane techniques described by Hopfer et al.(11) and by Klip et al.(12), respectively. Both were measured at room temperature. A $20 \mu \mathrm{l}$ aliquot of the suspension of vesicles was carefully placed in the bottom of a polystyrene test tube. An equal volume of $2.0 \mathrm{~mm}$ $\left[{ }^{3} \mathrm{H}\right]$ glucose or $10 \mu \mathrm{M}\left[{ }^{3} \mathrm{H}\right]$ phlorizin solution containing $100 \mathrm{~mm}$ mannitol, $10 \mathrm{~mm}$ Tris-HEPES ( $\mathrm{pH} 7.5$ ), and $100 \mathrm{~mm} \mathrm{NaSCN}$ was placed as a separate drop at the bottom of the tube. The assays of glucose uptake and phlorizin binding were started by rapid mixing using a vortex mixer and terminated after 15 and $60 \mathrm{~s}$, respectively, by dilution with $2.5 \mathrm{ml}$ of ice-cold $1 \mathrm{~mm}$ Tris- $\mathrm{HCl}$ buffer ( $\mathrm{pH} 7.0$ ) containing $250 \mathrm{~mm}$ $\mathrm{NaCl}$. The diluted sample was immediately transferred onto a nitrocellulose filter $(0.45-\mu \mathrm{M}$ pore size, Schleicher Schuell, Inc.) and rapidly rinsed further with $2.5 \mathrm{ml}$ of ice-cold $250 \mathrm{~mm} \mathrm{NaCl}$ containing $1 \mathrm{~mm}$ Tris- $\mathrm{HCl}$ buffer $\left(\mathrm{pH} \mathrm{7.0)}\right.$. Both $\mathrm{Na}^{+}$dependent glucose uptake and phlorizin binding activity were calculated by subtracting the amounts of $\left[{ }^{3} \mathrm{H}\right]$ glucose incorporated and bound $\left[{ }^{3} \mathrm{H}\right]$ phlorizin, respectively, with $100 \mathrm{~mm} \mathrm{KSCN}$ in place of $\mathrm{NaSCN}$ in the assays as above. These assays were done within $8 \mathrm{~h}$ after the rats had been sacrificed.

4. Sucrase assay and protein determination. An aliquot of the suspension of brush-border membrane vesicles was used for the assay of sucrase activity. Sucrase activity was determined by the method of Dahlqvist (10). Protein concentration was determined by the method of Lowry et al.(13) using bovine serum albumin as standard. Statistical analysis was carried out by Student's $t$-test.

5. Chemicals. Streptozotocin and phlorizin were purchased from Sigma Chemical Co. Glucose oxidase was obtained from Worthington Biochemical Co. The $D-\left[{ }^{3} \mathrm{H}\right]$ glucose and $\left[{ }^{3} \mathrm{H}\right]$ phlorizin were purchased from New England Nuclear Corp. All other reagents were of analytical grade.

\section{RESULTS}

1. Sucrase activity of intestinal brush-border membrane vesicles obtained from streptozotocin-induced diabetic and control rats

As shown in Table 1, the increases of sucrase activity in diabetic rats were

Table 1. Specific activity of sucrase in brush-border membrane vesicles of control and diabetic rat small intestine.

\begin{tabular}{lll}
\hline & Control & Diabetic \\
& \multicolumn{1}{c}{$(\mu \mathrm{mol} / \mathrm{mg}$ protein $/ \mathrm{h})$} \\
\hline Jejunum & $49.6 \pm 7.3^{\mathrm{b}}$ & $62.8 \pm 2.7$ \\
Ileum & $17.5 \pm 2.2$ & $44.9 \pm 5.2^{\mathrm{a}}$ \\
\hline
\end{tabular}

Results are expressed as means $\pm \mathrm{SE}$ of 8 animals. ${ }^{\text {a }}$ Significantly different from control $(p<0.01)$. ${ }^{\mathrm{b}}$ Significantly different from ileum $(p<0.01)$. 
moderate in jejunal and marked in ileal brush-border membrane vesicles. The results were consistent with those obtained with homogenates (data not shown). The recoveries of sucrase activity in the membrane vesicles were about $40 \%$ from those of corresponding homogenates.

2. Changes in D-glucose uptake by intestinal brush-border membrane vesicles obtained from streptozotocin-induced diabetic rats

In the presence of an inwardly-directed sodium gradient, D-glucose is transiently accumulated inside brush-border membrane vesicles, attaining a concentration which is several-fold higher than that in the medium $(11,14)$. Therefore, we investigated the changes in D-glucose uptake in the presence of NaSCN by brush-border membrane vesicles obtained from control and diabetic rat small intestines. As shown in Fig. 1, glucose uptake increased significantly both for the jejunum and ileum of diabetic rats compared with those of control rats. Glucose uptake by brush-border membrane vesicles exhibits a Michaelis-Menten type kinetics with glucose concentrations (11). Therefore, in order to investigate whether there are some changes in kinetic properties, such as affinity constant $\left(K_{t}\right)$ and the maximum glucose uptake $\left(V_{\max }\right)$, glucose uptake at various concentrations of glucose was measured with brush-border membrane vesicles of diabetic and control rat intestines. The $K_{\mathrm{t}}$ and $V_{\max }$ values were estimated according to Eadie-Scatchard plot. As shown in Table 2, the values of $K_{\mathrm{t}}$ for glucose uptake in diabetic rat jejunum and ileum were almost identical with those from control rats, whereas $V_{\max }$ values of diabetic rat jejunum and ileum increased significantly compared with those of control rats. These results indicated that experimental diabetes caused an increase in the number of the glucose transporter molecules.

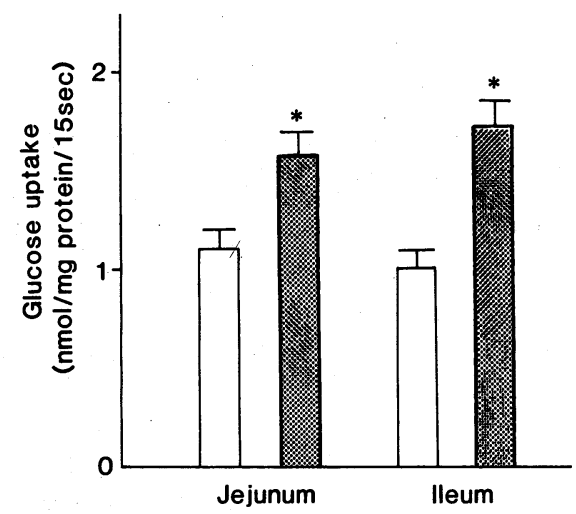

Fig. 1. Sodium-dependent glucose uptake by brush-border membrane vesicles of diabetic rat small intestine. Results are expressed as means \pm SE of 8 animals. Sodium-dependent glucose uptake was calculated by subtracting the amount of substrate in the presence of $\mathrm{KSCN}$ from that in the presence of NaSCN. * Significantly different from control rat at $p<0.01 . \square$, control rat; $\square$, diabetic rat. 
Table 2. Kinetic parameters of glucose uptake by brush-border membrane vesicles of diabetic rat small intestine.

\begin{tabular}{llllll}
\hline & \multicolumn{2}{c}{$\begin{array}{c}K_{\mathrm{t}} \\
(\mu \mathrm{M})\end{array}$} & & & \multicolumn{2}{c}{$\begin{array}{c}V_{\max } \\
(\mathrm{nmol} / \mathrm{mg} \text { protein })\end{array}$} \\
\cline { 2 - 3 } \cline { 5 - 6 } \cline { 5 - 6 } Jejunum & Control & Diabetic & & Control & Diabetic \\
\hline Ileum & $550 \pm 19$ & $535 \pm 9$ & & $1.84 \pm 0.24$ & $2.68 \pm 0.36^{\mathrm{a}}$ \\
& $527 \pm 17$ & $518 \pm 34$ & & $1.59 \pm 0.40$ & $2.74 \pm 0.25^{\mathrm{a}}$ \\
\hline
\end{tabular}

Results are expressed as means $\pm \mathrm{SE}$ of 4 samples. $K_{\mathrm{t}}$ and $V_{\max }$ values are estimated

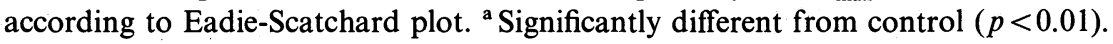

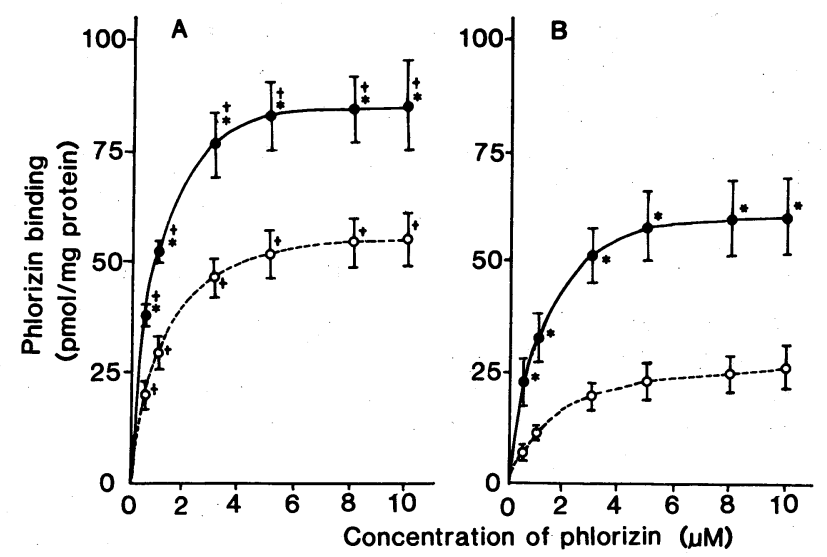

Fig. 2. Sodium-dependent phlorizin binding activity to brush-border membrane vesicles from diabetic rat small intestine. Results are expressed as means $\pm \mathrm{SE}$ of 8 animals. Sodium-dependent phlorizin binding was calculated by subtracting the amount of the ligand bound in the presence of $\mathrm{KSCN}$ from that in the presence of NaSCN. * Significantly different from control rat at $p<0.01 .{ }^{\dagger}$ Significantly different from ileum of the same group at $p<0.01$. $\bullet$, diabetic specimen; $\bigcirc$, control. A, Jejunum; B, Ileum.

3. Changes in phlorizin binding to brush-border membrane vesicles of rat with streptozotocin-induced diabetes

Phlorizin is a potent competitive inhibitor and serves as a ligand specific for $\mathrm{Na}^{+}$, D-glucose cotransporter $(1,2)$. Therefore, we investigated the changes in phlorizin binding to brush-border membrane vesicles obtained from control and diabetic rat small intestines. As shown in Fig. 2, the maximum phlorizin binding $\left(B_{\max }\right)$ to vesicles increased significantly both for the jejunum and ileum of diabetic rats compared with those for control rats, whereas half-maximum binding concentrations appeared unchanged. To obtain the dissociation constant $\left(K_{\mathrm{d}}\right)$ and $B_{\max }$, these values were analyzed according to Scatchard plot (Fig. 3), where slopes 


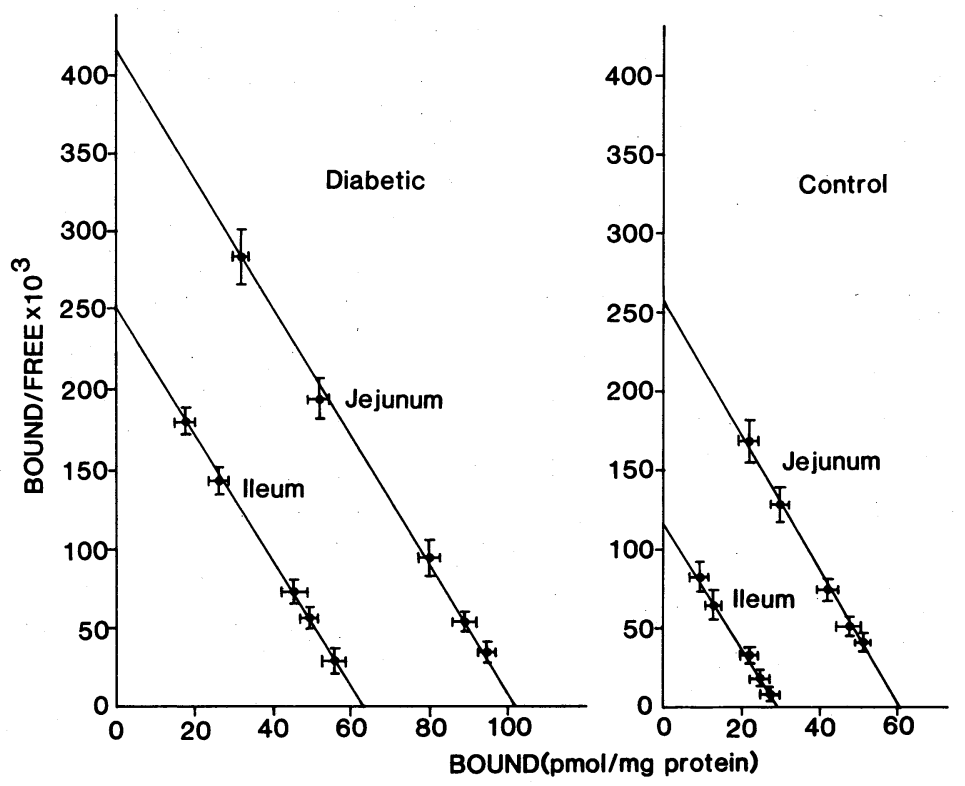

Fig. 3. Scatchard plots of the data shown in Fig. 2.

Table 3. Kinetic parameters of phlorizin binding to brush-border membrane vesicles of diabetic rat small intestine.

\begin{tabular}{lccccc}
\hline & \multicolumn{2}{c}{$\begin{array}{c}K_{\mathrm{d}} \\
(\mu \mathrm{M})\end{array}$} & & \multicolumn{2}{c}{$\begin{array}{c}B_{\max } \\
(\mathrm{pmol} / \mathrm{mg} \text { protein })\end{array}$} \\
\cline { 2 - 3 } \cline { 5 - 6 } & Control & Diabetic & & Control & Diabetic \\
\hline Jejunum & $5.59 \pm 0.39$ & $5.63 \pm 0.46$ & & $63.8 \pm 8.4^{\mathrm{b}}$ & $115.3 \pm 8.9^{\mathrm{a}, \mathrm{b}}$ \\
Ileum & $6.76 \pm 0.25$ & $5.19 \pm 0.57$ & & $30.8 \pm 4.4$ & $67.3 \pm 9.6^{\mathrm{a}}$ \\
\hline
\end{tabular}

Results are expressed as means $\pm \mathrm{SE}$ of 4 samples. ${ }^{\text {a }}$ Significantly different from control $(p<0.01)$. ${ }^{\mathrm{b}}$ Significantly different from ileum $(p<0.01)$.

represent $K_{\mathrm{d}}$ and intercepts on abscissa $B_{\max }$. As shown in Table 3, the values of $K_{\mathrm{d}}$ for phlorizin binding for diabetic rat jejunum were almost identical with those for control rats, and the difference of values for ileum was not significant, whereas $B_{\max }$ values increased significantly both for the jejunum and ileum of diabetic rats compared with those for control rats. These results suggested an increase in the number of glucose transporters in the brush-border membrane vesicles of the diabetic rat intestine. 


\section{DISCUSSION}

It has been demonstrated that glucose absorption and disaccharidase activities are increased in the small intestine of experimentally induced diabetic rats (3-8). In our previous study, we reported that the transmural potential difference $(\Delta \mathrm{PD})$ on transport of glucose derived from disaccharides was increased in diabetic rats, and this increase was ascribed mainly to the increased activity of glucose transport system, but not the increase of disaccharidase activities (9).

In the present study, to further assess the molecular basis, the glucose transport system was investigated with brush-border membrane vesicles from diabetic rat intestine. The results clearly showed that glucose uptake by, and phlorizin binding to, brush-border membrane vesicles increased significantly both in the jejunum and ileum of diabetic rat intestine compared with those of control rats. These results suggested the increase in the activity of the $\mathrm{Na}^{+}$, glucose cotransporter. Moreover, our kinetic studies showed the increases in $V_{\max }$ of glucose uptake and $B_{\max }$ of the binding of phlorizin but not $K_{\mathrm{t}}$ and $K_{\mathrm{d}}$, suggesting that the number of the glucose transporters was increased. Among possible interpretations of diabetic change in $V_{\max }$ for glucose transport, the first is the induction of the number of glucose transporters as suggested previously by Thomson (15) with the intact intestinal tissue. An alternative explanation is the changes in the electrochemical gradient for $\mathrm{Na}^{+}$during the coupled $\mathrm{Na}^{+}$, glucose cotransport (4). However, this view is not likely on the basis of recent findings by Fedorak et al. (16). They showed that alanine and 3-O-methylglucose transport were enhanced in the ileum of diabetic rats, but sulfate absorption, a sodium-dependent system, was not enhanced simultaneously. If the increased transport in diabetes is due to the changes in diabetic membrane somehow to sustain a higher driving force for transport, all $\mathrm{Na}^{+}$-dependent transport processes are expected to be increased. With respect to the possible changes in the membrane lipid, Gourley et al.(17) have analyzed the lipid composition and the viscosity of microvillus membrane from diabetic rats and found them to be similar to those from control rats. The uptake of glucose in diabetic rat intestine is further influenced by variations in dietary composition and the amounts of food intake. These features are under investigation with brush-border membrane vesicles from diabetic rat upon dietary manipulation.

\section{REFERENCES}

1) Toggenburger, G., Kessler, M., Rothstein, A., Semenza, G., and Tannenbaum, C. (1978): Similarity in effects of $\mathrm{Na}^{+}$gradient and membrane potentials on D-glucose transport by, and phlorizin binding to, vesicles derived from brush borders of rabbit intestinal mucosal cells. J. Membr. Biol., 40, 269-290.

2) Toggenburger, G., Kessler, M., and Semenza, G. (1982): Phlorizin as a probe of the small-intestinal $\mathrm{Na}^{+}, \mathrm{D}$-glucose cotransporter. A model. Biochim. Biophys. Acta, 688, 557-571. 
3) Schedl, H. P., and Wilson, H. D. (1971): Effects of diabetes on intestinal growth and hexose transport in the rat. Am. J. Physiol., 220, 1739-1745.

4) Hopfer, U. (1975): Diabetes mellitus: Changes in the transport properties of isolated microvillus membranes. Proc. Natl. Acad. Sci. U.S.A., 72, 2027-2031.

5) Nakabou, Y., Ishikawa, Y., Misaki, A., and Hagihira, H. (1980): Effect of food intake on intestinal absorption and mucosal hydrolases in alloxan diabetic rats. Metabolism, 29, 181-185.

6) Olsen, W. A., and Korsmo, H. (1975): Enhancement of intestinal sucrase activity in experimental diabetes: The role of intraluminal factors. J. Lab. Clin. Med., 85, 832-837.

7) Olsen, W. A., and Korsmo, H. (1977): The intestinal brush border membrane in diabetes. Studies of sucrase-isomaltase metabolism in rats with streptozotocin diabetes. J. Clin. Invest., 60, 181-188.

8) Goda, T., Hosoya, N., and Moriuchi, S. (1983): Changes of the activity and content of sucrase-isomaltase complex in the intestinal mucosa during the development of streptozotocin-induced diabetes in rats. J. Nutr. Sci. Vitaminol., 29, 571-578.

9) Tsuji, Y., Yamada, K., Hosoya, N., and Moriuchi, S. (1985): Changes of sugar-evoked transmural potential differences in intestine of rats with streptozotocin-induced diabetes. J. Nutr. Sci. Vitaminol., 31, 317-326.

10) Dahlqvist, A. (1964): Method for assay of intestinal disaccharidases. Anal. Biochem., 7, 18-25.

11) Hopfer, U., Nelson, K., Perrotto, J., and Isselbacher, K. (1973): Glucose transport in isolated brush border membrane from rat small intestine. J. Biol. Chem., 248, 25-32.

12) Klip, A., Grinstein, S., and Semenza, G. (1979): Partial purification of the sugar carrier of intestinal brush border membranes. Enrichment of the phlorizin binding component by selective extractions. J. Membr. Biol., 51, 47-73.

13) Lowry, O. H., Rosebrough, N. J., Farr, A. L., and Randall, R. J. (1951): Protein measurement with Folin phenol reagent. J. Biol. Chem., 193, 265-275.

14) Kessler, M., Acuto, O., Storelli, C., Murer, H., Müller, M., and Semenza, G. (1978): A modified procedure for the rapid preparation of efficiently transporting vesicles from small intestinal brush border membranes. Their use in investigating some properties of D-glucose and choline transport systems. Biochim. Biophys. Acta, 506, 136-154.

15) Thomson, A. B. R. (1981): Uptake of glucose into the intestine of diabetic rats. Effects of variations in the effective resistance of the unstirred water layer. Diabetes, 30, 247255.

16) Fedorak, R. N., Chang, E. D., and Field, M. (1984): Intestinal adaptation to streptozotocin-induced diabetes: in vitro changes in sugar, amino acid and $\mathrm{SO}_{4}$ transport. Abstract. Gastroenterology, 86, 1074.

17) Gourley, G. R., Korsmo, H. A., and Olsen, W. A. (1983): Intestinal mucosa in diabetic rats: Studies of microvillus membrane composition and microviscosity. Metabolism, 30, 1053-1058. 